opening, which was then closed. Five days later the needles were withdrawn without difficulty. The patient made a normal recovery his pain ceased, his appetite returned, and in three months he had regained his normal weight and was the picture of health.

\section{Angioma of the Mcningcs.}

A man of 45 had suffered for year's from fits at long intervals. Recently the fits had become more frequent and severe, and they Recently the fits had become more frequent and severe, and they
were now accompanied by loss of consciousness. They were were now accompanied by loss of consciousness. They wcre to the face and leg. Beyond a slight increase in the deep reflexes on the left side there was little to be made out on a neurological cxamination. On exposing the right Rolandic area by means of an osteoplastic flap formed with my craniotome, and on opening the dura, a mass of huge interlacing veins was found occupving the whal a m the whole of the upper portion of the field, and forming a vascula tumour about three inches in diameter. seemed practicable the dura was closed, and on to its outer surface were sutured six radium needles, each $2 \mathrm{~cm}$. long and containing $2 \mathrm{mg}$. of element. The needles were arranged as the spokes of a wheel, and the attached threads were brought out through the central hole in the bone flap. The bone was replaced, the threads were brought through the scalp flap, and the scalp was sutured into position.

The after-history of the case was somewhat remarkable. Three days later he noticed a weakness of the left arm, which developed next day into a complete paralysis. On the following day the needles were drawn out by the threads without difficulty, having been in position for five days, A week later he had completely recovered the use of the arm. There has been no recurrence of the fits, and he seems to be in perfect health.

These cases are only chosen to show the effects which radium can produce in a great variety of situations, and under conditions where the ordinary methods of surgery are not applicable. 'The brilliant work of Regaud in Paris, of Hayward Pinch and his assistants at the London Radium Institute, of Keynes at St. Bartholomew's, of Cade and his colleagues at Westminster, of Birkett of Manchester, and of many others, has shown that in cancer of the uterus, of the skin, of the breast, and of the mouth and tongue, success can be depended upon as a routine. It has rather been my aim to show how wide are the powers of radium, and that where we have failed it is rather our method of application than our weapon itself which is at fault. I am convinced that we are only on the threshold of a great adventure; I feel that a new world of surgical technique is opening before us; I am beginning to belicre that at last we hold in our hands the key to the cure of cancer.

\section{SOME EFFECTS OF DEEP X RAYS UPON THE CELLS OF THE BLOOD.}

4 PRELIMINARY NOTE ON A PHAGOCYTIC TEST. BY

F. A. KNOTT, M.D., M.R.C.P., D.P.H., HAEMATOLOGIST TC GUY'S HOSPITAL; AND

W. L. WATT, C.M.G., M.D.,

SURGEON IN CHARGE OF DEEP THERAPY DEPARTMENT, GUY'S HOSPITAL.

Tre experiments about to be described are the result of an attempt to observe in vitro the effect of the rays employed in deep $x$-ray therapy upon the living cells of the blood. The rays used were the hardest that it has been possible to generate up to the present. The apparatus used was the latest type of constant potential generator with valie rectification, voltage 220,000 , metalix water-cooled tube, filtration $1 \mathrm{~mm}$. copper and $3 \mathrm{~mm}$. aluminium.

That these rays have a destructive effect upon living cells is too well known to need discussion here. It is not clear, however, whether such rapid disappearance of white blood cells as occurs, for example, in cases of leukaemia undergoing deep $x$-ray therapy can be accounted for purely by this destructive effect on the cel!s themselves, or whether other factors come into play. It is more than probable that whatever direct injury occurs to the cells is caused by the secondary rays thrown out by all elements of sufficiently high atomic weight which obstruct the path of the original hard rays in their course through the body. The greatest cell destruction would then occur in the neighbourhood of foci producing these secondary rays, and the importance of this factor was clearly brought out in
our first experiment.
A large block of clean paraffin wax was cast with outside dimensions of approximately 6 in. by $4 \mathrm{in}$. by $4 \mathrm{in}$. The block was divided longitudinally so as to form a closefitting lid over a little central chamber hollowed out in the lower half of the block. The capacity of the chamber was about 2 c.cm. Freshly drawn, oxalated blood could be placed in the chamber and submitted to controlled irradiation.

The methods used in examining the blood will be described in the next paragraph. For the moment the important point to note is that if blood was placed in the sinple paraffin block described, practically no lethal effect could be produced upon the blood within one and a half hours, however intense the irradiation. If, howerer, the little central chamber was surrounded by a layer of material relatively opaque to $x$ rays, damage to the cells was very soon apparent. The most satisfactory method of producing secondary rays near the blood was found to be surrounding the little chamber within the paraffin block with a layer of blotting paper soaked in a solution of metallic salts, so that the paper was covered with a thin layer of wax and was separated from the blood only by this layer. Before the metal-containing paper was inserted, blood from cases of splenomedullary leukaemia placed in the chamber was submitted to full radiation for two hoursabout six times the therapentic deep therapy dose-but no definitely lethal effect upon the white cells could be detected. When the paper was inserted, damage to the cells could be observed after only fifteen minutes' similar irradiation. The more closely the chamber was surrounded by metallic salt-in other words, the more intense the secondary radiations-the more quickly were the white cells affected.

\section{Methods of Observing Damage to Cells.}

To examine individual blood cells while the blood was being irradiated in the chamber small samples were removed at intervals and thin films spread. These were stained by all the usual histological methods, but no certain differences could be made out to distinguish normal from damaged cells. The oxidase reaction was applied to the films and vital staining with cresyl blue attenpted, but again no differences could be demonstrated. The only positive results were obtained when samples of blood, before and after irradiation, were kept under sterile conditions at laboratory temperatures up to three days, at the end of which wet film preparations stained with neutral red were made. It then appeared that nuclear degeneration had occurred more quickly in the irradiated white cells. But the differences were not sufficiently sharp to justify the method for quantitative purposes. It must also be explained that blood counts performed upon the samples of blood in the chamber during and many hours after irradiation showed no reduction in the number of red or white cells present. Furthermore, prolonged agitation of the blood in a mechanical shaker did not result in any breaking up of irradiated cells. In short, no actual reduction of the number of cells, red or white, in the blood could be demonstrated and no changes in staining reaction detected.

\section{The Phagocytic Power of White Cells.}

It seemed, therefore, that, in order to demonstrate the cell damage caused by the rays, some direct biological method must be used. Experiments were then made upon the phagocytic power of the white cells towards staphylococci, and this method has, we think, given definitely promising results.

Using a marked teat pipette, small equal quantities of blood were drawn during irradiation from the chamber at fre- or ten-minute intervals, and to each was added the same amount of an emulsion of staphylococci in 1 per cent. citrate in normal saline. After allowing these mixtures to remain in the $37^{\circ}$ incubator for five to ten minutes films were spread and stained with Leishman's stain, the whole procedure following the lines of an opsonic index determination. Direct examination of the films gave a reading of the percentage of white cells in any particular sample still retaining their phagerytic power. Loss of this power was taken to indicate a lethal effect upon the white cells. 
The important points noted as a result of this experiment are as follows:

(a) If a normal or leukaemic blood be placed in the chamber and irradiated as described, complete loss of all phagocytic power in the polymorphs is observed within about thirty-five minutes.

(b) This loss of phagocytic power appears to be quite permanent. The experiment was varied in different ways and samples of blood given time to recover before examination, 'but no return of phagocytic power could be detected.

(c) In passing, it was noted that in fresh unirradiated bloods phagocytic power was possessed only by the relatively mature forms of polymorphonuclear and hyaline leucocytes. It is of interest that myeloblasts, myelocytes, and transitionals appear to have no phagocytic power towards the usual types of bacteria.

(d) The lethal effect appeared to begin upon the polymorphs at about the same point, whether in normal or leukaemic bloods.

Thus the experiments with the paraffin block appeared clearly to demonstrate a directly destructive effect by the rays on the white cells, and also that this destructive effect was produced mainly, if not entirely, by the secondary radiations and not by the original hard rays.

Some success with this method in vitro at once suggested applications of the test for phagocytic power upon the white cells of patients undergoing deep therapy treatment.

Direct Tests upon Irradiated Patients.

In this respect the first fact to be observed was that if blood from a leukaemic patient be taken twenty-four hours after deep therapy treatment and, as already described, mixed with staphylococci, a considerable number of the polymorphs, although they stain quite normally, will be found to have lost their phagocytic power. The test was therefore systematically applied to patients during actual irradiation. It was found that, whatever part of the body was irradiated, within about twenty minutes the percentage of actively phagocytic polymorphs began to fall. If the test was repeated at intervals a few other important points could be noted-namely :

(á) After full irradiation of the spleen in, for example, a case of splenomedullary leukaemia, although the first treatment will result in loss of phagocytic power in a considerable number of the polymorphs, the percentage varying according to the dose given and the width of the field irradiated, the proportion of white cells which disappear from the circulating blood within the next few hours is much less than this, and it takes a few days for all these damaged cells to be removed from the circulation.

(b) While the damaged cells are disappearing, a number of new normal polymorphs are being produced, so that a point is reached at which production and destruction balance. each other and the immediate fall in the white count ceases. In some cases it may rise again slightly, and a test of the phagocytic power of the cells then shows that the rise is due to fresh normal cells.

(c) If these irradiated cases be, however, further watched it will often be found that although all the damaged nonphagocytic cells have disappeared from the circulation and a secondary rise, as above described, may even have occurred, still the fall in the white count continues. At this stage all the cells are normal in their phagocytic power, and the falling count can be accounted for only by some directly depressant action possessed by the rays upon the source of the cellsnamely, the reticulo-endothelial system.

In short, it is evident that we can account for most of the immediate fall in the white count of irradiated cases of leukaemia by the directly lethal effect of the secondary radiations upon the blood cells themselves. But the more gradual later fall probably arises from depression of the white cell producing mechanism. Much further work must be done to confirm and elaborate such points as these, but the initial facts are put forward to illustrate the way in which the methods described appear to throw some light upon the mechanism of the deep $x$-ray treatment of leukaemia.

\section{Irradiation and Normal Blood.}

Let us next consider the effect of deep therapy upon the cells of patients showing a normal blood picture. Here, again, according to the intensity of the irradiation which their lesions have required, there is also a fall in the phagocytic power of their polymorphs and a gradual removal of the damaged cells from the circulating blood. This effect lasts for a few days, until, reproduction of new cells becoming gradually more effective, the white count slowly returns to normal.

It will at once be clear, however, that the ordinary methods of blood counting in any of these cases do not, at any particular moment, tell us how many of the patient's leucocytes are normal effective cells. Some such test as we have described must be applied before we can be sure they are functionally norimal. We believe, therefore, that the test of phagocytic power in the polymorphs may have useful clinical application in the case of patients treated with deep therapy or other irradiation. Whether the results will be helpful in diagnosis and progniosis is at present under investigation. Meanwhile it may be worth while to note the following points.

The first concerns the known fact that actively septic patients, leukaemic or otherwise, are not usually favourable subjects for irradiation. The septic element often becomes more pronounced, and the demonstration of the rapid disappearance of phagocytic power in the leucocytes of these patients throws some light upon this antiseptic failure. If these patients must be irradiated, it is well to apply the test for phagorytic power so that this function of their white cells shall not be driven too low. For this purpose an ordinary white count is not sufficient.

Secondly, it is clear that the initial fall in a patient's white count, following irradiation, is a function of the number of directly damaged cells. By noting the loss of phagocytic power, even while irradiation is actually taking place, we can make an immediate estimate of what the fa!l in the white count will be and control the dosage accordingly. Tsing ordinary methods of blood counting, this fall has actually occurred before we can estimate it. Furthermore, in patients whose white cell count is already low, and in whom it is undesirable to cause too great a fall, a useful method of controlling dosage and of forecasting the white cell loss is the application of the phagocytic test. Irradiation may well be stopped at a point where not more than 25 per cent. of the patient's polymorphs have lost their phagocytic power. Any future irradiation would depend upon the restoration or otherwise of phagocytic power.

Summary.

A method is described of estimating the phagocutic power of the polymorphs in patients undergoing deep $x$-ray treatment, and some possible clinical applications of the test in treatment control are put forward.

Some results with the test are discussed in relation to the theories concerning the effects of irradiation upon leukaemic and other patients.

\section{TONSIL PUNCTURE: A NEW METHOD OF INVESTIGATION.}

BY

\section{JEFFREY RAMSAY, M.D., AND C. M. PEARCE, M.B. M.R.C.P., \\ HONORARY PHYSICIAN, F.R.C.S., BLACKBCRN AND EAST LANCASHIRE ROYAL INFIRMARY.}

Disease of the tonsils, as a clinical entity, has been known for many centuries. Celsus, who was born in Rome about the time of Christ, devotes a whole chapter to the subject in his De Medicina, and makes many references to tonsillar diseases in other portions of the work.

In our day acute and chronic affections of the tonsils rank among the diseases which are frequently encountered. The work which follows is concerned with the modern viewpoint of the tonsil as a source of focal sepsis. Among such sources the tonsils occupy an important position. Our present investigations have convinced us that this importance has not been exaggerated and that hidden infection in the tonsils may be responsible for much ill health, both definite and indefinite. Irwin Moore $^{1}$ gives a list of fiftyone diseases which may result from focal infection of tonsillar origin. The results of such infection may reach and affect any part of the body by way of the lymphatics or the blood stream. Moore states that the general opinion is that after the age of 5 year's nearly all tonsils are 